\title{
An on-line instrument for mobile measurements of the spatial variability of hexavalent and trivalent chromium in urban air
}

\author{
Andrey Khlystov*, Yilin Ma \\ Department of Civil and Environmental Engineering, 127B Hudson Hall, Box 90287, Durham, NC 27708-0287, USA
}

Received 5 June 2006; received in revised form 2 September 2006; accepted 8 September 2006

\begin{abstract}
The Steam-Jet Aerosol Collector-long Pathlength Absorbance Spectroscopy (SJAC-LPAS), an on-line continuous instrument for mobile measurements of spatial distribution of water-soluble hexavalent and trivalent chromium in ambient aerosols, has been developed and is presented here. The system collects particles with the SJAC and analyzes the collected sample on-line using the diphenycarbazide (DPC) colorimetric method. By using a Teflon AF (Amorphous Fluoropolymer) liquid core wave guide, the limit of detection has been significantly improved, allowing on-line measurements at ambient concentrations. The limit of detection for $\mathrm{Cr}(\mathrm{VI})$ is $0.2 \mathrm{ng} \mathrm{m}^{-3}$. Water-soluble $\mathrm{Cr}$ (III) can also be measured by oxidizing it to $\mathrm{Cr}(\mathrm{VI})$ in a parallel line using hydrogen peroxide before the detection with the DPC method. The concentration of $\mathrm{Cr}(\mathrm{III})$ is then determined as the difference between the two lines ( $\mathrm{Cr}(\mathrm{VI})$ and $\mathrm{Cr}(\mathrm{VI})$ plus $\mathrm{Cr}(\mathrm{III})$ ). The instrument was specifically designed to be used on a mobile platform to study spatial distribution of the pollutant within a city on a scale of $100 \mathrm{~m}$. Special attention was given to the time resolution and the stability of the instrument performance under driving conditions. The time resolution of the instrument is $15 \mathrm{~s}$. At a typical driving speed of $30 \mathrm{~km} \mathrm{~h}^{-1}$ the instrument can detect variations in chromium concentration ("hot spots") on the scale of about $150 \mathrm{~m}$. The instrument has proven to operate reliably and capture temporal and spatial variability of $\mathrm{Cr}(\mathrm{VI})$ concentration during four mobile measurement campaigns in Wilmington, DE.
\end{abstract}

(C) 2006 Elsevier Ltd. All rights reserved.

Keywords: Hexavalent chromium; Trivalent chromium; Mobile measurements; Spatial distribution

\section{Introduction}

In the atmosphere chromium is primarily found in the airborne particulate matter (PM) in two valence states: trivalent chromium $(\mathrm{Cr}(\mathrm{III}))$ and hexavalent chromium (Cr(VI)) (Kotas and Stasicka, 2000). Trivalent chromium is relatively nontoxic,

\footnotetext{
*Corresponding author. Tel.: + 19196605209 ; fax: +19196605219 .

E-mail address: andrey@duke.edu (A. Khlystov).
}

while hexavalent chromium is extremely harmful (Cohen et al., 1993; Singh et al., 1999) and is classified by the US Environmental Protection Agency (EPA) as a group A inhalation carcinogen (EPA, 1984). Because of these differences in the effects of $\mathrm{Cr}(\mathrm{III})$ and $\mathrm{Cr}(\mathrm{VI})$, speciation of chromium in ambient PM is vital for correct evaluation of aerosol toxicity.

Most sources of $\mathrm{Cr}(\mathrm{VI})$ are localized, originating from such activities as metal plating, dye and pigment manufacturing, cleaning of various metal 
parts in automobile and aircraft industry (Carlton, 2003; Paustenbach et al., 1991; Wang et al., 1999). It is thus possible that there are regions of elevated concentrations ("hotspots") caused by the proximity of such activities. Characterization of such "hotspots" is critical for assessing population exposure on a neighborhood scale (of the order of $100 \mathrm{~m}$ ). Such areas cannot be located and characterized by means of stationary monitoring. However, they can be identified and characterized by means of mobile sampling during which on-line instruments are placed on a vehicle and measurements are performed while driving mapping the spatial distribution (Bukowiecki et al., 2002; Weijers et al., 2004; Westerdahl et al., 2005).

Mobile measurements place a number of constraints on the instrumentation. They require a high time resolution: a spatial resolution of $100 \mathrm{~m}$ at a driving speed of $30 \mathrm{~km} \mathrm{~h}^{-1}$ requires a time resolution of $10 \mathrm{~s}$. The instrument needs to be sensitive enough to distinguish elevated concentrations above the background, which for $\mathrm{Cr}(\mathrm{VI})$ is often below $1 \mathrm{ng} \mathrm{m}^{-3}$ (Nriagu et al., 1988). The instrument also needs to be stable at the conditions of the driving, i.e. have minimum interference from the vibrations and acceleration/deceleration induced by the moving vehicle.

The common method for $\mathrm{Cr}(\mathrm{VI})$ in ambient aerosol involves filter sampling with the consequent analysis of the filter extract (e.g. US EPA methods 7196A and 0218.6). Extensive reviews of available methods can be found elsewhere (e.g. Ashley et al., 2003; Kotas and Stasicka, 2000). Filter measurements require long sampling times (usually $24 \mathrm{~h}$ ), which precludes them from being used on a mobile platform. Samanta et al. (2001) have reported a system for automated measurements of $\mathrm{Cr}(\mathrm{VI})$ in ambient aerosols, which uses a set of automatically washed filters to collect and extract aerosol species. The extract is pre-concentrated using an ionexchange column and $\mathrm{Cr}(\mathrm{VI})$ is determined by flow-injection analysis. The detection limit of the system is $5 \mathrm{ng} \mathrm{m}^{-3}$. However, the time resolution $(15 \mathrm{~min})$ is still too low to be applicable for mobile measurements.

We present here an instrument for measurements of $\mathrm{Cr}(\mathrm{VI})$ in ambient air that has been specifically designed to meet the requirements of mobile measurements. It should be noted, that the main value of mobile measurements is in locating areas with concentrations elevated relatively to the city average, i.e. detecting concentration differences within a city. Therefore, most attention is directed to characterization of the instrument's ability to detect differences in ambient concentration on a small scale, and less to the absolute accuracy of the instrument.

\section{Experimental}

\subsection{Aerosol sampling and collection}

The schematic of Steam-Jet Aerosol Collectorlong Pathlength Absorption Spectroscopy (SJACLPAS) system is shown in Fig. 1. Ambient aerosol is collected with the Steam-Jet Aerosol Collector (SJAC) (Khlystov et al., 1995). The air is sampled at a rate of $16.71 \mathrm{~min}^{-1}$ through a Teflon-coated

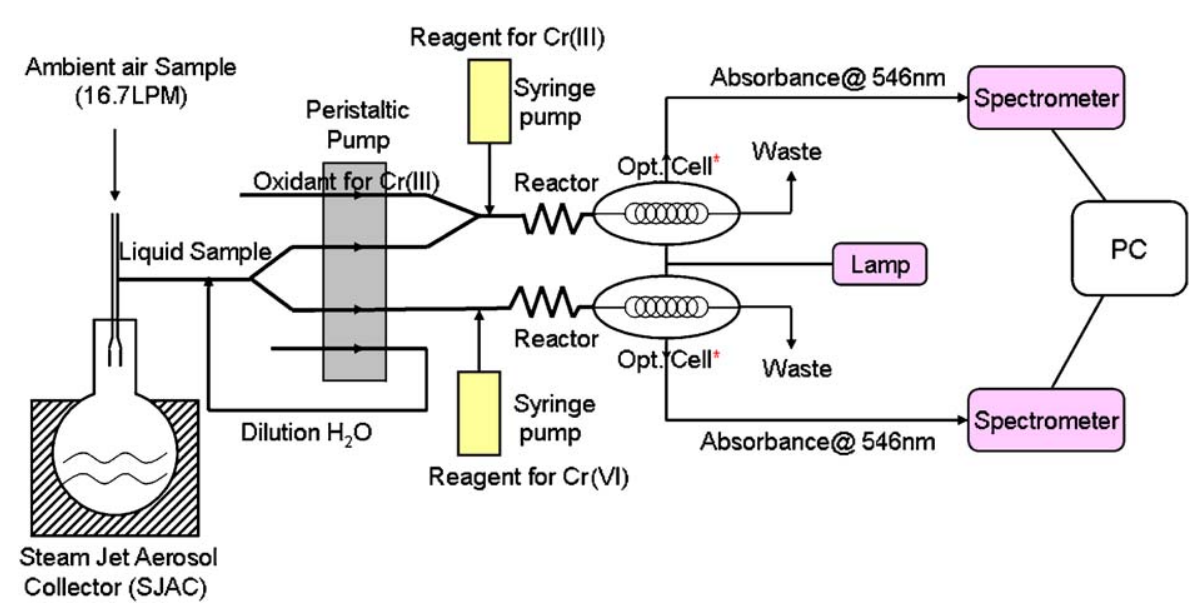

Fig. 1. General schematic of SJAC-LPAS system for measurements of hexavalent and trivalent chromium in ambient aerosol. The use of Cr(III) line is optional. The SJAC is described in detail in Khlystov et al. (1995). 
PM2.5 cyclone (URG Inc., Chapel Hill, NC). The SJAC operates by injecting steam into the sampled air stream, which causes water vapor to condense on the sampled aerosol particles. Particles grow due to water condensation to a size of at least $1 \mu \mathrm{m}$ in diameter and are collected by a cyclone. The SJAC quantitatively collects particles down to a few nanonmeters in diameter (collection efficiency 99\%) (Khlystov et al., 1995). The collected liquid containing dissolved aerosol species is continuously pumped out with an eight channel Dynamax RP-1 (Rainin Instrument Co., Emeryville, CA) peristaltic pump and is directed to the LPAS-CFA, where the concentration of $\mathrm{Cr}(\mathrm{VI})$ is determined.

\subsection{LPAS-CFA system}

The LPAS-CFA system uses the well established diphenycarbazide (DPC) colorimetric method (Allen, 1958). Liquid core waveguide (LCW) optical cells have been used to increase the sensitivity of colorimetric methods (Lei et al., 1983) and have been successfully applied to $\mathrm{Cr}(\mathrm{VI})$ determination with the DPC method (Li et al., 2003; Yao and Byrne, 1999). A LCW provides long optical pathlength by constraining light propagation within a liquid medium which has a higher refractive index (RI) than the surrounding solid tubing (Lei et al., 1983). Teflon AF-2400 (DuPont), has an RI of 1.29 and many of the desirable chemical properties of Teflon (Altkorn et al., 1997).

Before entering the LPAS-CFA system, the collected sample is diluted with a constant flow of double-deionized water to ensure sufficient flow for $\mathrm{Cr}(\mathrm{VI})$ and $\mathrm{Cr}(\mathrm{III})$ analysis. It should be noted that the $\mathrm{Cr}$ (III) line is optional and the detection limit for $\mathrm{Cr}(\mathrm{VI})$ can be improved by switching off the $\mathrm{Cr}$ (III) line, in which case no dilution is needed. The diluted sample then passes through a debubbler. The bubble formation in the system is further prevented by using an exit restriction to increase backpressure. The flow after the debubbler is divided equally for the $\mathrm{Cr}(\mathrm{VI})$ and $\mathrm{Cr}(\mathrm{III})$ analysis. A computer-controlled syringe pump (Versa 6, Kloehn Ltd., Las Vegas, NV) is used for reagent delivery. Super-serpentine mixer (1/16 "OD and 0.030 'ID, $2 \mathrm{~m}$ long, GlobalFIA Inc., Fox Island, WA) is used for mixing and reacting the sample with the DPC reagent. The serpentine mixer has a minimal axial dispersion, which is an important factor for a fast instrument response.
The sample is then directed to the LCW optical cell. The design of the LCW cell follows that described elsewhere (Yao and Byrne, 1999). A $5 \mathrm{~m}$ long Teflon AF-2400 tubing (0.031 "OD and 0.008" ID, Random Technologies, San Francisco, CA) is used as the LCW. Two optical fibers (200 and $600 \mu \mathrm{m})$ are used to connect the cell to a LS-1 Tungsten Halogen Light Source and a USB2000 Miniature Fiber Optic spectrometer (all from Ocean Optics, Dunedin, FL). Absorbances at the detection wavelength of $546 \mathrm{~nm}$ and the non-absorbing wavelength of $700 \mathrm{~nm}$ are used to calculate chromium concentration, with the non-absorbing wavelength serving to compensate for any eventual drifts in the signal.

The setup for the $\mathrm{Cr}$ (III) analysis is similar to that for $\mathrm{Cr}(\mathrm{VI})$ analysis except that the liquid sample is oxidized by adding a solution of hydrogen peroxide (Andersen, 1998) and directing the flow through a $1 \mathrm{~m}$ long super-serpentine mixer before mixing it with the DPC reagent. Cr(III) concentration is then determined as the difference between the two lines.

\subsection{Reagents and standards}

All solutions were prepared with double deionized water and using analytical grade reagents. 1,5diphenylcarbazide (Alfa Aesar, Ward Hill, MA), acetone, $\mathrm{NaOH}, \mathrm{K}_{2} \mathrm{Cr}_{2} \mathrm{O}_{7}, \mathrm{CrK}\left(\mathrm{SO}_{4}\right)_{2}$ (all from Fisher, Pittsburgh, PA), $\mathrm{H}_{2} \mathrm{O}_{2}$ (Acros Organics, Geel, Belgium), were obtained as indicated. Tracemetal grade sulfuric acid was obtained from EM Science (Darmstadt, Germany). The following reagent compositions were used. The DPC solution was prepared by dissolving $0.167 \mathrm{~g}$ of the reagent in $100 \mathrm{ml}$ of acetone and then mixed with $1.67 \%$ $\mathrm{H}_{2} \mathrm{SO}_{4}$ solution in $1: 1$ volume ratio. $0.1 \% \mathrm{H}_{2} \mathrm{O}_{2}$ solution was prepared by diluting $0.143 \mathrm{ml}$ of $\mathrm{H}_{2} \mathrm{O}_{2}$ with $0.1 \mathrm{M} \mathrm{NaOH}$ solution to $100 \mathrm{ml}$.

\section{Results and discussion}

\subsection{Calibration and limit of detection}

The analytical part of the system was calibrated using $\mathrm{Cr}(\mathrm{VI})$ and $\mathrm{Cr}(\mathrm{III})$ standard solutions. The absorbance signals for both $\mathrm{Cr}(\mathrm{VI})$ and $\mathrm{Cr}(\mathrm{III})$ have linear relationship with chromium concentration (Fig. 2). The limit of detection (LOD) for the Cr(VI) and $\mathrm{Cr}$ (III) aerosol measurements, defined as three times the standard deviation of the blank (reagents + deionized water) measured in laboratory 


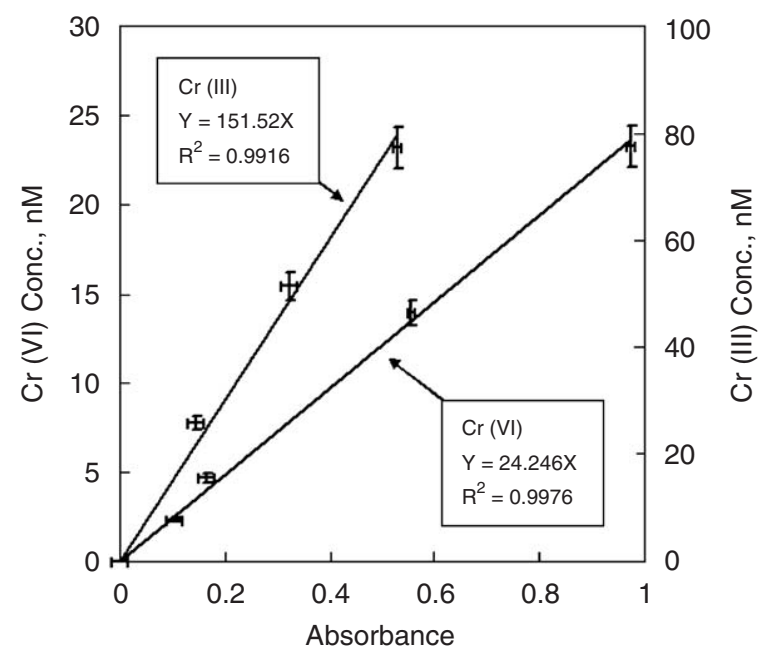

Fig. 2. Calibration curves of $\mathrm{Cr}(\mathrm{VI})$ and $\mathrm{Cr}(\mathrm{III})$ standard solutions.

conditions, is $0.19 \mathrm{ng} \mathrm{m}^{-3}$ for $\mathrm{Cr}(\mathrm{VI})$ and $1.9 \mathrm{ng} \mathrm{m}^{-3}$ for $\mathrm{Cr}$ (III). When the system is running on a moving vehicle, the vibrations and frequent acceleration/ deceleration caused by the driving affect the system stability. Data obtained from a moving vehicle showed a larger standard deviation, and thus a higher LOD of $0.48 \mathrm{ngm}^{-3}$ for $\mathrm{Cr}(\mathrm{VI})$. If the $\mathrm{Cr}$ (III) line is switched off, the LOD for $\mathrm{Cr}(\mathrm{VI})$ under driving conditions is lowered to $0.24 \mathrm{ngm}^{-3}$, because no dilution is required to provide a sufficient flow to the detector.

\subsection{Response time}

The time resolution of the instrument was tested by observing the signal change in response to a step change in chromium concentration. Due to the time needed to transfer the sample from the point of collection to the optical cell, there is a considerable delay before a change in signal is detected. The delay times (as defined by the time difference between the input concentration change and the $50 \%$ change of the signal) are $8 \mathrm{~min} 30 \mathrm{~s}$ for the $\mathrm{Cr}(\mathrm{VI})$ line and $9 \mathrm{~min} 57 \mathrm{~s}$ for the $\mathrm{Cr}(\mathrm{III})$ line, reproducible to within $3 \mathrm{~s}$. During the mobile measurements this delay is accounted for by correcting the sampling times by the appropriate delay values. To assure accurate correction, the clocks of the on-board global positioning system (GPS) and the SJAC-LPAS data acquisition are synchronized to a second before each measurement.
Due to the mixing processes in the system, a step change in the input concentration appears as an Sshaped curve. The system response function, which is the system response to an infinitely sharp pulse input ( $\delta$-signal) can be found by differentiating the $\mathrm{S}$-shaped response curve with respect to time. The time resolution of the instrument was assessed by convoluting the response function with a rectangular pulse function of different duration representing a plume. Our objective was to be able to observe plumes having a concentration at least two times higher than the background. System responses to plumes of different duration are shown in Fig. 3. Due to the mixing processes in the instrument the plume signals are smeared out. When the plume duration is $15 \mathrm{~s}$ or longer, the signal due to the plume can be distinguished from the noise of the background (the instrument noise is $10 \%$ of the measured concentration). Time resolution of $15 \mathrm{~s}$ corresponds to a spatial resolution of about $150 \mathrm{~m}$, if measurements are made at a driving speed of $30 \mathrm{~km} \mathrm{~h}^{-1}$.

\subsection{Field deployment}

The SJAC-LPAS system has been installed on the Duke University mobile laboratory equipped with a GPS along with a set of other instruments and successfully deployed within the enhanced delaware air toxics assessment study (EDATAS) during four 1-week campaigns held near downtown Wilmington,

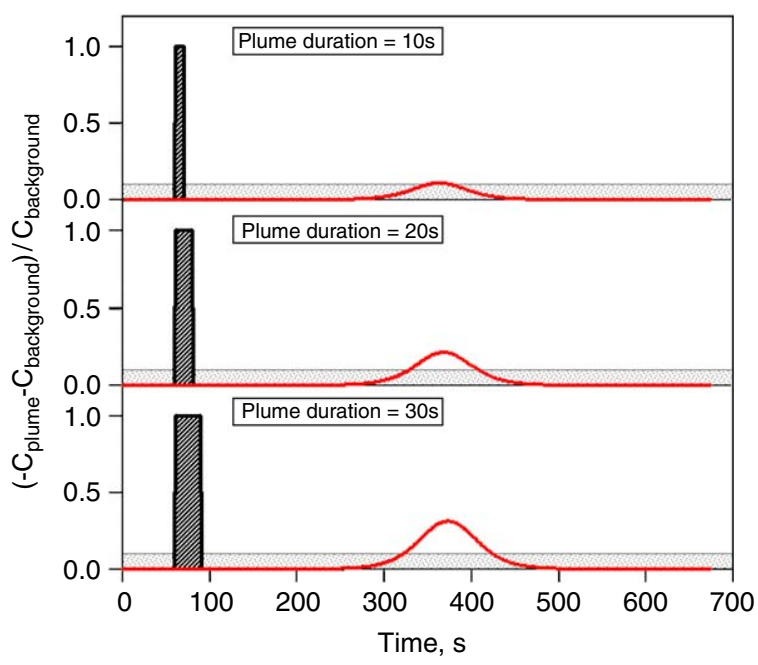

Fig. 3. Modeled system response to plumes of different duration. The $Y$-axis shows increase in concentration relatively to background concentration $\left(\left(C_{\text {plume }}-C_{\text {backgr }}\right) / C_{\text {backgr }}\right)$. The grey area represents the noise level. 
DE. Measurements were made while driving on a specifically designed route passing through several residential neighborhoods. The main objectives of the deployment were to evaluate the SJAC-LPAS system performance for measuring $\mathrm{Cr}(\mathrm{VI})$ in ambient aerosols, to characterize the temporal and spatial variability of the pollutants on a neighborhood scale, and to provide detailed fine-scale data for model evaluation with $1 \mathrm{~km}$ grid resolution.

The field measurements demonstrated that the SJAC-LPAS is suitable for mobile measurements of chromium species in the ambient aerosols. Although the ambient $\mathrm{Cr}(\mathrm{VI})$ concentration was within the measurable range, the concentration of watersoluble Cr(III) was usually below the LOD. Therefore, the instrument was mostly run measuring $\mathrm{Cr}(\mathrm{VI})$ only (the $\mathrm{Cr}$ (III) line was switched off) to decrease the detection limit for $\mathrm{Cr}(\mathrm{VI})$.

Fig. 4 shows the sub-grid variability distributions measured during the summer campaign of EDATAS. Each grid is $1 \mathrm{~km} \times 1 \mathrm{~km}$. The plots for each grid represent histograms showing the number of observations as a function of the observed concentration in $\mathrm{ng} \mathrm{m}^{-3}$. This demonstrates the capability of the instrument to detect and quantify the variability between and within the grids, which can be used for verification of air quality models and for better assessment of the exposure of an urban population to hexavalent chromium compounds on a neighborhood scale. A detailed analysis of the data will be presented in a forthcoming paper.

\section{Conclusions}

The steam jet aerosol collector-long pathlength absorbance spectroscopy (SJAC-LPAS), an automated near real-time instrument for hexavalent chromium and water-soluble trivalent chromium in ambient aerosol has been developed for application on a mobile platform. The system collects particles into liquid water and analyzes the collected sample with diphenycarbazide (DPC) colorimetric method using a Teflon AF liquid core waveguide. The LOD of the system is $0.2 \mathrm{ng} \mathrm{m}^{-3}$ for $\mathrm{Cr}(\mathrm{VI})$ and $1.9 \mathrm{ng} \mathrm{m}^{-3}$ for $\mathrm{Cr}$ (III). The system can capture the variability of chromium concentration on the time scale of $15 \mathrm{~s}$. During four field campaigns the instrument has proven to be a useful tool for detecting and quantifying spatial variability within a city on a $100 \mathrm{~m}$ scale.

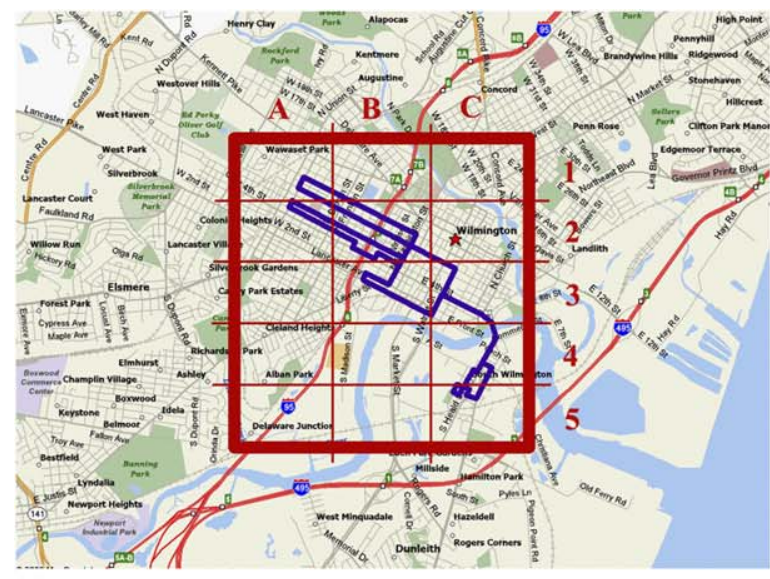

(a)

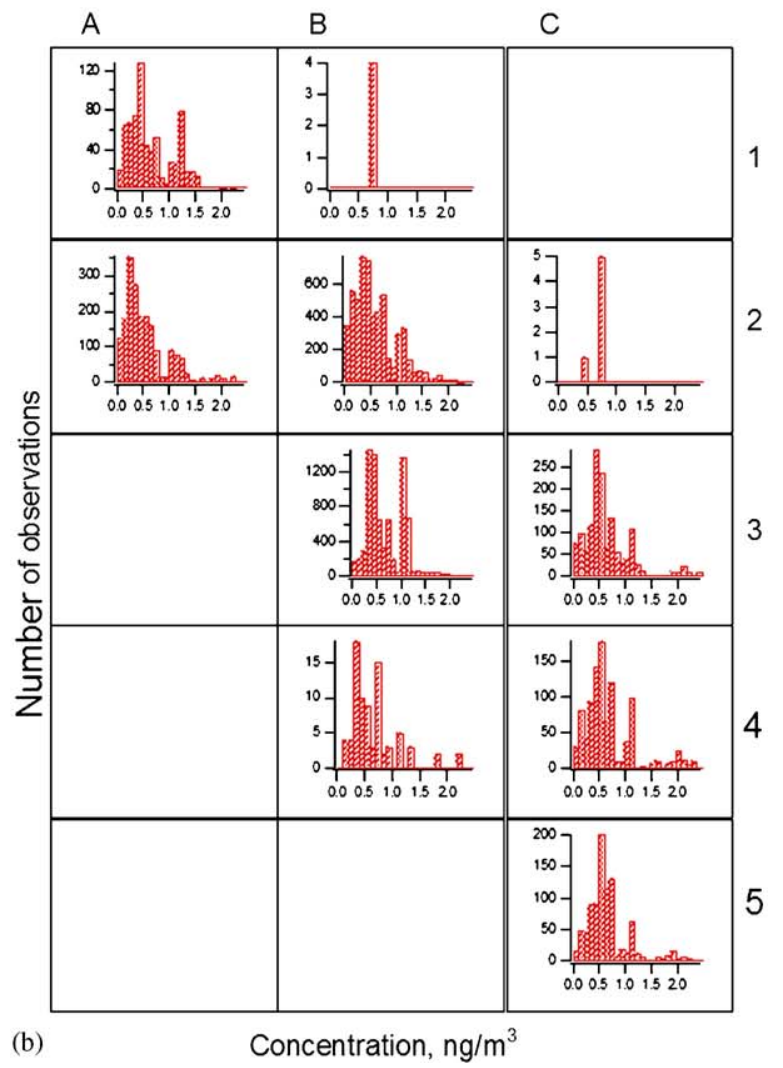

Fig. 4. (a) A map of Wilmington, DE showing the driving route and the grid used to calculate sub-grid variability distributions, Each grid is $1 \mathrm{~km} \times 1 \mathrm{~km}$. (b) Sub-grid variability distributions of $\mathrm{Cr}(\mathrm{VI})$ concentration observed during the summer intensive campaign. The histograms show the number of observations as a function of $\mathrm{Cr}(\mathrm{VI})$ concentration in $\mathrm{ng} \mathrm{m}^{-3}$.

\section{Acknowledgments}

The measurements in Wilmington, DE were conducted as part of the Enhanced Delaware Air 
Toxics Assessment Study, which was supported by the US EPA and partly by the Delaware Department of Natural Resources and Environmental Control (DNREC). The authors thank Joe Martini of DNREC, Vlad Isakov and Jason Ching of the US EPA for their contributions to this work.

\section{References}

Allen, T.L., 1958. Microdetermination of chromium with 1,5diphenylcarbohydrazide. Analytical Chemistry 30, 447-450.

Altkorn, R., Koev, I., VanDuyne, R.P., Litorja, M., 1997. Lowloss liquid-core optical fiber for low-refractive-index liquids: fabrication, characterization, and application in Raman spectroscopy. Applied Optics 36, 8992-8998.

Andersen, J.E.T., 1998. Introduction of hydrogen peroxide as an oxidant in flow injection analysis: speciation of $\mathrm{Cr}$ (III) and Cr(VI). Analytica Chimica Acta 361, 125-131.

Ashley, K., Howe, A.M., Demange, M., Nygren, O., 2003. Sampling and analysis considerations for the determination of hexavalent chromium in workplace air. Journal of Environmental Monitoring 5, 707-716.

Bukowiecki, N., Dommen, J., Prevot, A.S.H., Richter, R., Weingartner, E., Baltensperger, U., 2002. A mobile pollutant measurement laboratory-measuring gas phase and aerosol ambient concentrations with high spatial and temporal resolution. Atmospheric Environment 36, 5569-5579.

Carlton, G.N., 2003. Hexavalent chromium exposures during full-aircraft corrosion control. Aiha Journal 64, 668-672.

Cohen, M.D., Kargacin, B., Klein, C.B., Costa, M., 1993. Mechanisms of chromium carcinogenicity and toxicity. Critical Reviews in Toxicology 23, 255-281.

EPA, 1984. Health Effects Assessment for Hexavalent Chromium. US EPA, Washington, DC.

Khlystov, A., Wyers, G.P., Slanina, J., 1995. The steam-jet aerosol collector. Atmospheric Environment 29, 2229-2234.

Kotas, J., Stasicka, Z., 2000. Chromium occurrence in the environment and methods of its speciation. Environmental Pollution 107, 263-283.
Lei, W., Fujiwara, K., Fuwa, K., 1983. Determination of phosphorus in natural-waters by long-capillary-cell absorption spectrometry. Analytical Chemistry 55, 951-955.

Li, Q.Y., Morris, K.J., Dasgupta, P.K., Raimundo, I.M., Temkin, H., 2003. Portable flow-injection analyzer with liquid-core waveguide based fluorescence, luminescence, and long path length absorbance detector. Analytica Chimica Acta 479, 151-165.

Nriagu, J.O., Pacyna, J.M., Milford, J.B., Davidson, C.I., 1988. Distribution and characteristic features of chromium in the atmosphere. In: Nriagu, J.O., Nieboer, E. (Eds.), Chromium in Natural and Human Environments. Wiley Interscience, New York, pp. 125-173.

Paustenbach, D.J., Rinehart, W.E., Sheehan, P.J., 1991. The health-hazards posed by chromium-contaminated soils in residential and industrial-areas - conclusions of an expert panel. Regulatory Toxicology and Pharmacology 13, 195-222.

Samanta, G., Boring, C.B., Dasgupta, P.K., 2001. Continuous automated measurement of hexavalent chromium in airborne particulate matter. Analytical Chemistry 73, 2034-2040.

Singh, J., Pritchard, D.E., Carlisle, D.L., McLean, J.A., Montaser, A., Orenstein, J.M., Patierno, S.R., 1999. Internalization of carcinogenic lead chromate particles by cultured normal human lung epithelial cells: formation of intracellular lead-inclusion bodies and induction of apoptosis. Toxicology and Applied Pharmacology 161, 240-248.

Wang, J., Ashley, K., Marlow, D., England, E.C., Carlton, O., 1999. Field method for the determination of hexavalent chromium by ultrasonication and strong anion exchange solid phase extraction. Analytical Chemistry 71, 1027-1032.

Weijers, E.P., Khlystov, A.Y., Kos, G.P.A., Erisman, J.W., 2004. Variability of particulate matter concentrations along roads and motorways determined by a moving measurement unit. Atmospheric Environment 38, 2993-3002.

Westerdahl, D., Fruin, S., Sax, T., Fine, P.M., Sioutas, C., 2005. Mobile platform measurements of ultrafine particles and associated pollutant concentrations on freeways and residential streets in Los Angeles. Atmospheric Environment 39, 3597-3610.

Yao, W.S., Byrne, R.H., 1999. Determination of trace chromium(VI) and molybdenum(VI) in natural and bottled mineral waters using long pathlength absorbance spectroscopy (LPAS). Talanta 48, 277-282. 